\title{
Leyes y Decretos Promulgados por el Gobierno Costarricense para Controlar a los Ciudadanos y Empresas de Países Enemigos con Residencia en Costa Rica durante la Segunda Guerra Mundial.
}

MA Gertrud Peters S Escuela de Historia, Universidad Nacional. MSc. Margarita Torres H. Escuela de Historia, Universidad Nacional. ${ }^{1}$

Este documento presenta el marco legal de las relaciones con los ciudadanos de países enemigos residentes en Costa Rica durante la Segunda Guerra Mundial, cuando el país le declaró la guerra a Japón, Alemania e Italia. Antes de ese momento, las relaciones diplomáticas se habían modificado conforme a la aparición de nuevos acontecimientos. De esta manera, el país, bajo el contexto de la política de Defensa Hemisférica de los Estados Unidos de América, inició un período de promulgación, eliminación y reforma de leyes, decretos y acuerdos en el entorno nacional e internacional.

El objetivo de estas disposiciones legales era limitar la influencia de las familias de ascendencia alemana, italiana y japonesa en la economía costarricense por medio del cambio en las leyes de extranjería, la limitación de sus actividades económicas y la enajenación de los activos de empresas y personas físicas de aquella nacionalidad.

Además de las leyes migratorias, del Bloqueo Económico, del control, venta forzada y expropiación de de bienes inmuebles, también se efectuaron detenciones y deportaciones de estos ciudadanos y sus familias a campos de concentración en los Estados Unidos de Norteamérica.

\footnotetext{
${ }^{1}$ Ambas profesoras e investigadoras de la Escuela de Historia de la Universidad Nacional, Costa Rica.

Este trabajo nace del proyecto de investigación "Cambios en la propiedad agrícola durante la Segunda Guerra Mundial en Costa Rica", de la Escuela de Historia de la Universidad Nacional.
} 
El investigador encontrará las leyes, decretos, medidas restrictivas, reglamentos y acuerdos que se emitieron entre 1939 y 1974 referentes a los asuntos de guerra y expropiaciones de bienes a los ciudadanos de los países enemigos de los aliados. La información siguiente está divida por año y número de ley o decreto, además se anotó la fecha de emisión, el asunto a tratar y qué institución la suscribió, a saber el Poder Ejecutivo, el Congreso, o las diversas carteras del gobierno. Se encuentran también documentadas las referencias de los documentos localizados en el Archivo Nacional de Costa Rica, concernientes a las discusiones en torno a las declaraciones y asuntos de guerra, así como los mensajes presidenciales ${ }^{2}$.

En este resumen de normas legales, el lector puede encontrar las distintas vías de control de los bienes de los ciudadanos del Eje, desde la justificación por la Defensa Nacional y Hemisférica, la restricción y anulación a las transacciones comerciales, el control por la Oficina de Coordinación y luego la Junta de Custodia, la expropiación fundamentada por utilidad pública, el congelamiento de fondos y la creación de bonos para financiar promesas de campaña política y nuevas obras públicas, hasta reformas constitucionales que lesionaban la propiedad privada y los derechos individuales de personas nacidas en suelo costarricense.

En este sentido, este documento puede considerarse de consulta obligada para los estudiosos de la historia política y de las relaciones internacionales de Costa Rica.

\footnotetext{
${ }^{2}$ Otras fuentes no han sido investigadas por las autoras del proyecto, será importante ahondar en nuevos documentos de carácter político y militar que se puedan encontrar en otros acervos documentales.
} 


\section{Listado de leyes y decretos}

Año 1939

No. 13

29 de setiembre de 1939

Regulación de las relaciones comerciales entre Alemania y Costa Rica, con motivo de la guerra. Poder Legislativo.

Año 1940

No. 377 de junio de 1940. Se crea la Oficina de Migración. Poder Legislativo.

No. 6318 de junio de 1940. Tarifa gradual a las mercaderías importadas mientras dura la Guerra. Poder Legislativo.

No. 1145 de julio de 1940. Unificación de fuerzas policíacas del país. Creación de la Policía Nacional. Poder Legislativo

No. 530 de setiembre de 1940. Acepta, aprueba y ratifica la Convención para la Administración Provisional de Colonias y Posesiones Europeas en América. Poder Ejecutivo.

No. 1825 de octubre de 1940. Autorizase al Poder Ejecutivo para que asuma todo el control sobre el café. Poder Legislativo.

\section{Año 1941}

No. 821 de abril de 1941. Se crea la Oficina de Migración. Poder Legislativo.

No. 129 de abril de 1941. Expulsión del alemán Karl Bayer Hunz. Consejo de Gobierno.

No. 221 de mayo e 1941. Expulsión de alemanes: Karl Josechop y Helgo Petersen. Casos del incendio de barcos. Consejo de Gobierno.

No .926 de junio de 1941. Prohibe la entrada de submarinos, etc., de las naciones beligerantes, en las aguas de Costa Rica. Poder Ejecutivo.

No. 9420 de agosto de 1941. Declara con lugar apelación de la Sociedad Guillermo Niehaus \& Co. a un acuerdo de la Municipalidad de San José. Cartera de Gobernación. 
No. 37122 de agosto de 1941. Máximo de fuerza armada que el Poder Ejecutivo debe mantener el servicio activo durante 1942. Poder Legislativo.

No. 92 de setiembre de 1941. Aprueba el reglamento que fija las condiciones de venta y exportación del café de la cosecha 1941-42. Poder Ejecutivo.

No. 16329 de setiembre de 1941. Declara inadmisible las funciones oficiales de Cónsules, Vicecónsules y Agentes Consulares alemanes en el territorio de la República. Poder Ejecutivo.

No. 4410 de octubre de 1941. Créase la "Oficina de Coordinación" dependiente de la Secretaría de Hacienda. Poder Legislativo.

No. 1214 de noviembre de 1941. Modifica Decreto No. 9 del 2 de setiembre de 1941, sobre venta y exportación de café para la cosecha 1941-1942. Poder Ejecutivo.

No. 28 de diciembre de 1941. Autorízase al Poder Ejecutivo para que declare la guerra al Japón. Poder Legislativo.

No. 38 de diciembre de 1941. Decreta estado de guerra entre la República de Costa Rica y el Imperio del Japón. Poder Ejecutivo.

No. 39 de diciembre de 1941. Suspéndase a juicio del Poder Ejecutivo las garantías individuales por cincuenta días. Poder Legislativo.

No. 1111 de diciembre de 1941. Decreta las medidas que se tomarán con motivo del estado de guerra en que se encuentra la República. $\underline{\text { Poder }}$ Ejecutivo.

No. 4411 de diciembre de 1941. Déjase sin efecto todas las licencias concedidas hasta la fecha por el Poder Ejecutivo para estaciones de radioaficionados. Poder Ejecutivo.

No. 4511 de diciembre de 1941. Exprópiese a favor de la Hacienda Militar la dinamita, materias explosivas, armas de toda clase y municiones que se encuentren en el país. Poder Ejecutivo.

No. 4711 de diciembre de 1941. Decreta las medidas tomadas para con los súbditos japoneses, alemanes e italianos que se encuentren en el país. Poder Ejecutivo. 
No. 4611 de diciembre de 1941. Exprópiese el derecho de usar y aprovechar la planta eléctrica y subestación de Miller Hermanos. Poder Ejecutivo.

No. 411 de diciembre de 1941. Decrétase el estado de guerra entre Costa Rica, Alemania e Italia. Poder Ejecutivo.

No. 1218 de diciembre de 1941. Decreta anuladas las matrículas para la posesión de armas, las cuales deberán renovarse. Poder Ejecutivo.

No. 5120 de diciembre de 1941. Decreta en que forma deben aplicarse las disposiciones que contiene el Decreto Ejecutivo No. 47 del 11 de diciembre de 1941. Restricciones a los alemanes y japoneses. Poder Ejecutivo.

No. 5226 de diciembre de 1941. Decreta prohibido todo acto de comercio entre personas residentes en Costa Rica y las que residen en Japón, Alemania e Italia. Poder Ejecutivo.

\section{Año 1942}

No. 17 de enero de 1942. Dicta las medidas necesarias para la ejecución del decreto que creó la Oficina de Coordinación referente a las personas y sociedades de las naciones en guerra con el país. Poder Ejecutivo.

No. 44 de febrero de 1942. Prohibe la exportación y re-exportación de aceites, grasas y otras materias primas para la industria. Poder Ejecutivo.

No. 624 de febrero de 1942. Dispone que la Oficina de Coordinación será la contralora de los bienes nacionales de los países en guerra con Costa Rica. Poder Ejecutivo.

No. 44 de marzo de 1942. Suspensión de garantías constitucionales por sesenta días. Poder Legislativo.

No. 925 de marzo de 1942. Crea la Junta de Custodia de la Propiedad para los nacionales de los países en guerra con Costa Rica. Poder Ejecutivo.

No. 16 de mayo de 1942. Suspensión de garantías constitucionales por sesenta días. Poder Legislativo.

No. 6627 de junio de 1942. Se ratifican, por ajustarse a los mandatos de la Constitución y a las necesidades de la Defensa Nacional, varios decretos del Poder Ejecutivo. Poder Legislativo. 
No. 212 de julio de 1942. Dispone que la Junta de Custodia de a Propiedad, ejerza las funciones que la ley le encomienda. Poder Ejecutivo.

No. 99 de julio de 1942. Suspenden por sesenta días las garantías constitucionales. Poder Legislativo.

No. 12029 de julio de 1942. Dispone que la Junta de Custodia pagará por accidentes de trabajo por actos de guerra. Poder Legislativo.

No. 27717 de agosto de 1942. Autoriza al Poder Ejecutivo para mantener en servicio activo el número de hombres necesarios. Poder Legislativo.

No. 283 de setiembre de 1942. Dispone que conforme al artículo $9^{\circ}$ de la Ley No. 66 del 28 de junio de 1942, la Junta de Custodia de la propiedad, dispondrá de los fondos congelados. Poder Ejecutivo.

No. 199 de setiembre de 1942. Suspenden por sesenta días las garantías constitucionales. Poder Legislativo.

No. 2913 de setiembre de 1942. Prohibe la circulación de billetes de los Estados Unidos de América, en el territorio de la República. Poder Ejecutivo.

No. 216 de setiembre de 1942. Reglamento de la venta y exportación de café para la cosecha 1942-43. Poder Ejecutivo.

No. 4017 de setiembre de 1942. Declara agotada la vía administrativa en la apelación de Guillermo Niehaus \& Co., sobre una resolución de la Junta de Custodia de la Propiedad. Cartera de Hacienda y Comercio.

No. 3429 de octubre de 1942. Reforma el Decreto Ejecutivo No. 29 del 13 de setiembre de 1942 que prohibe la circulación de billetes de los Estados Unidos de América. Poder Ejecutivo.

No. 26 de noviembre de 1942. Suspenden hasta por sesenta días las garantías constitucionales. Poder Legislativo.

No. 528 de noviembre de 1942. Modifica al artículo $5^{\circ}$ del reglamento para la venta y exportación de café, cosecha 1942-43. Poder Ejecutivo. 
No. 2612 de diciembre de 1942. Decreto-ley de Orden Público acerca de la Junta de Custodia de la Propiedad. Ley de Bloqueo Económico. Poder Legislativo.

Año 1943

No. 515 de mayo de 1943. Autoriza al Poder Ejecutivo para constituir gravámenes de cédulas hipotecarias sobre los bienes inmuebles expropiados. Poder Legislativo.

No. 427 de enero de 1943. Dicta Reglamento de la Junta de Custodia de la Propiedad. $\underline{\text { Poder Ejecutivo. }}$

No. 530 de enero de 1943. Expropiación a Guillemo Niehaus de las Haciendas Victoria y Lindora. Poder Ejecutivo.

No. 630 de enero de 1943. Expropiación a Hübbe e hijos de finca La Caja. Poder Ejecutivo.

No. $7 \quad 10$ de febrero de 1943. Expropiación de maquinaria a japoneses en una finca de Barranca. Poder Ejecutivo.

No. 810 de febrero de 1943. Expropiación a Guillermo Niehaus de finca Poró. Poder Ejecutivo.

No. 1018 de febrero de 1943. Autoriza la circulación de doscientos bonos de la Defensa 6\%. Poder Ejecutivo.

No. 116 de marzo de 1943. Autoriza la circulación de cuatrocientos bonos de la Defensa 6\%-1942. Poder Ejecutivo.

No. 1210 de marzo de 1943. Eleva a rango de Embajada la Legación de La República ante el Gobierno de los Estados Unidos de América. Poder Ejecutivo.

No. 1211 de marzo de 1943. Aclara decreto de expropiación de los Ingenios Victoria y Lindora. Poder Ejecutivo.

No. 1312 de marzo de 1943. Ratifica decreto de expropiación de La Caja. Poder Ejecutivo.

No. 151 de abril de 1943. Adiciona reglamento de Junta de Custodia Poder Ejecutivo.

No. 165 de abril de 1943. Autoriza circulación de trescientos bonos de la Defensa de 6\%-1942. Poder Ejecutivo. 
No. 176 de abril de 1943. Expropia a Guillermo Niehaus la finca Poró. Poder Ejecutivo.

No. 187 de abril de 1943. Expropiación a Guillermo Niehaus de las fincas Waldeck y Barrantes. Poder Ejecutivo.

No. 197 de abril de 1943. Expropia propiedad del Club Alemán de Costa Rica. Poder Ejecutivo.

No. 2116 de abril de 1943. Aclara conceptos del derecho referente a expropiaciones. Poder Ejecutivo.

No. 2319 de abril de 1943. Adiciona decreto referente a la Junta de Custodia. Poder Ejecutivo.

No. 2420 de abril de 1943. Reforma decreto No. 12 referente a expropiaciones de Haciendas Victoria y Lindora. Poder Ejecutivo.

No. 2526 de abril de 1943. Expropia a Guillermo Niehaus \& Compañía de un camión marca "Mercedes". Poder Ejecutivo.

No. 2626 de abril de 1943. Expropia a Bernhard Busken Arns de la finca "La Flora". Poder Ejecutivo.

No. 2727 de abril de 1943. Expropia varios inmuebles de Wilhelm Peters Schuster. Poder Ejecutivo.

No. 2827 de abril de 1943. Expropia una finca de Fernand Franz. $\underline{\text { Poder }}$ Ejecutivo.

No. 2930 de abril de 1943. Expropia a Gustavo Haeberle Schemp, una partida de hierro negro. Poder Ejecutivo.

No. 303 de mayo de 1943. Expropia a Guillermo Niehaus \& Co. la lancha Santa Elena. Poder Ejecutivo.

No. 327 de mayo de 1943. Expropia el café beneficiado de las listas pertenecientes a súbditos de los países incluidos en listas proclamadas. Poder Ejecutivo.

No. $33 \quad 8$ de mayo de 1943. Expropia una finca en Alajuelita a Federico Karl Schad. Poder Ejecutivo.

No. 3410 de mayo de 1943. Expropia unos bienes inmuebles a Miller Hnos. y otros. Poder Ejecutivo.

No. 3613 de mayo de 1943. Autoriza la circulación de seiscientos Bonos de la Defensa 6\%, 1942. Poder Ejecutivo. 
No. 3715 de mayo de 1943. Expropiación de fincas de Fernando Grebien Bechaider y otros. Poder Ejecutivo .

No. 3815 de mayo de 1943. Expropiación de bienes de Reich Kapahmnke.

Poder Ejecutivo.

No. 3915 de mayo de 1943. Expropiación de bienes de Herst Von Peterdoff y Fehlan. Poder Ejecutivo.

No. 4022 de mayo de 1943. Se deja sin efecto la expropiación de los bienes de Fernando Grebien Bechaider y otros. Poder Ejecutivo,

No. 4124 de mayo de 1943. Expropiación de bienes alemanes. Poder Ejecutivo.

No. 4224 de mayo de 1943. Expropiación de bienes alemanes. Poder Ejecutivo.

No. 4331 de mayo de 1943. Bonos de Defensa autorizados por el Pode Ejecutivo. Poder Ejecutivo.

No. 441 de junio de 1943. Se adicionan decretos referentes a expropiaciones, abarcando bienes inmuebles, semovientes y maquinaria. Poder Ejecutivo.

No. 4511 de junio de 1943. Expropiación de muebles del Hotel Marbella y enseres de Erna de Sandweg. Poder Ejecutivo.

No. 4826 de junio de 1943. Se incluyen en la expropiación a Miller Hnos., las concesiones eléctricas e implementos de las fincas. Poder Ejecutivo.

No. 5627 de abril de 1943. Autoriza el remate de una tubería existente en finca Lindora. Cartera de Hacienda.

No. 120 de febrero de 1943. Confirma una resolución de la Junta de Protección a la Agricultura de la Caña, en apelación de Guillermo Niehaus. Cartera de Fomento.

No. 242 de julio de 1943. Reforma a la Constitución de la república sobre propiedad individual y garantías sociales. Poder Legislativo.

No. 337 de julio de 1943. Reforma a la Ley de Extranjería sobre costarricenses que sirvan en ejércitos contra las Potencias del Eje. Poder Legislativo. 
No. 12021 de agosto de 1943. Sobre procedimientos para el cobro de deudas de nacionales de países en guerra con Costa Rica, a favor de costarricenses. Poder Legislativo.

No. 111 de octubre de 1943. Reforma de los artículos 19 y 20 de la Ley No. 26 del 12 de diciembre de 1942. Sobre avalúo y remate de bienes sometidos a la Junta de Custodia. Poder Legislativo.

No. 4928 de diciembre de 1943. Se reforman los párrafos 3 y 4 del artículo 19 de la Ley No. 11 del 1 de octubre de 1943 referente a la forma de pago en Bonos de la Defensa, para el que compre bienes rematados por la Junta de Custodia. Poder Legislativo.

No. 5229 de diciembre de 1943. Se fijan condiciones bajo las cuales pueden los extranjeros ejercer el comercio en Costa Rica. Poder Legislativo.

No. 527 de agosto de 1943. Bonos de Defensa. Poder Ejecutivo.

No. 5523 de agosto de 1943. Se decreta expropiación de Hacienda La Caja. Poder Ejecutivo.

No. 6218 de setiembre de 1943. Autoriza la circulación de Bonos de Defensa. Poder Ejecutivo.

No. 724 de setiembre de 1943. Reglamento para las condiciones de venta y exportación de café, cosecha 1943-44. Poder Ejecutivo.

No. 684 de octubre de 1943. Bonos de Defensa. Poder Ejecutivo.

No. 7219 de octubre de 1943. Hipoteca de cédulas sobre Hacienda La Caja. Poder Ejecutivo.

No. 7322 de octubre de 1943. Se equiparan los súbditos españoles a los costarricenses para los efectos del artículo tercero de la Ley No. 26 del 12 de diciembre de 1942. Poder Ejecutivo.

No. 7425 de octubre de 1943. Se crea el Comité Nacional para la Defensa Política y se fijan sus atribuciones. Poder Ejecutivo.

No. 754 de noviembre de 1943. Se declara la importación de frijoles mientras dure el estado bélico . Poder Ejecutivo.

No. 765 de noviembre de 1943. Se autoriza circulación de Bonos de Defensa. Poder Ejecutivo.

No. 8124 de noviembre de 1943. Bonos de Defensa. Poder Ejecutivo.

No. 8510 de diciembre de 1943. Bonos de Defensa. Poder Ejecutivo. 
No. 8718 de diciembre de 1943. Se expropian fincas de Hans Rehaag Weing. Poder Ejecutivo.

No. 8523 de julio de 1943. Se autoriza a la Junta de Custodia para la venta de una finca que fue de Gustavo Haeberle Schemp. artera de Hacienda y Comercio.

No. 8818 de diciembre de 1943. Expropiación de fincas de Marta Trejos González. Poder Ejecutivo.

\section{Año 1944}

No. 13 de enero de 1944. Se determinan los territorios que según el artículo primero de la Ley No. 26 del 12 de diciembre de 1942 deben considerarse sujetos a las medidas de bloqueo económico. Poder Ejecutivo.

No. 317 de enero de 1944. Se obliga a las compañías importadoras de gasolina a declarar el monto de las existencias de este producto. Poder Ejecutivo.

No. 518 de enero de 1944. Se señala la intervención de la Junta de Defensa Económica en la importación y distribución de llantas de hule. Poder Ejecutivo.

No. 82 de febrero de 1944. Bonos de Defensa. Poder Ejecutivo.

No. 234 de mayo de 1944. Se decreta la explotación por el SNE de las empresas de planta eléctrica y oxígeno que fueron expropiadas a Miller \& Hnos y Bruno Miller Lacher. Poder Ejecutivo.

No. 265 de mayo de 1944. Se modifica el artículo noveno del decreto No. 4 del 27 de enero de 1943 sobre atribuciones del Secretario de la Junta de Custodia. Poder Ejecutivo.

No. 117 de mayo de 1944. Se expropian inmuebles pertenecientes a F. Reimers y Cía. Poder Ejecutivo.

No. 222 de mayo de 1944. Se establece un timbre especial para el pago de derechos destinados para gastos de la Oficina de Defensa Económica. Poder Ejecutivo.

No. 426 de mayo de 1944. Se expropian fincas de Marta Trejos González administradas por la Junta de Custodia. Poder Ejecutivo.

No. 1012 de junio de 1944. Se decreta la expropiación de fincas de Ricardo Krusse Levestein, administradas por la Junta de Custodia. Poder Ejecutivo. 
No. 1223 de junio de 1944. Se destina una suma en Bonos de la Defensa como contribución del Estado al pago del precio fijado para las fincas que constituyen las Haciendas Victoria, Poró y Tacares. Poder Ejecutivo.

No. 114 de junio de 1944. Se cancela la inscripción de nacionalidad costarricense a Ernesto Ludovico Rechnitzer R. Cartera de Relaciones Exteriores.

No. 20630 de agosto de 1944. Se crea la Oficina de Defensa Económica, para aplicar con arreglo a las disposiciones de esta ley todas las medidas de emergencia de carácter económico a que obligue la situación actual de guerra. Poder Legislativo.

No. 20726 de agosto de 1944. Se modifican algunos artículos de la Ley de Extranjería y Naturalizaciones No. 25 del 13 de mayo de 1889 y sus posteriores reformas. Poder Legislativo.

No. 529 de setiembre de 1944. Se reforman los artículos cinco, nueve, once y doce de la Ley No. 206 del 30 de agosto de 1944 que creó la Oficina de Defensa. Poder Legislativo.

No. 2617 de noviembre de 1944. Se determina la forma en que deben ser indemnizados los costarricenses que hayan sufrido daños por la guerra. Poder Legislativo.

Año 1945

No. 4329 de enero de 1945. Modifica la Ley No. 26 del 12 de diciembre de 1942 y autoriza al Poder Ejecutivo para emitir Vales de expropiación a fin de invertir en ellos los fondos congelados en poder de la Junta de Custodia, cuyo producto se empleará en pagar deudas de la Administración Pública. Poder Legislativo.

No. 4429 de enero de 1945. Se modifica la Ley No. 36 del 23 de diciembre de 1944, autorizando al Banco Nacional de Costa Rica (BNCR) para emplear divisas extranjeras en la importación de artículos de primera necesidad. Poder Legislativo.

No. 217 de junio de 1945. Se interpreta el párrafo segundo del artículo 22 de la Ley No. 26 del 12 de diciembre de 1942, relativo a indemnizaciones para trabajadores que hayan sufrido daños y perjuicios por actos de guerra. Poder Legislativo.

No. 237 de junio de 1945. Se autoriza al Pode Ejecutivo para que expropie una finca de Guillermo Niehaus \& Co. y la venta al BNCR. Poder Legislativo.

No. 4114 de junio de 1945. Se reforman artículos $4,12,16,17,18,19,20$ y 21 de la Ley No. 26 del 12 de diciembre de 1942 y leyes 
posteriores reformatorias, relativas a las atribuciones de la Junta de Custodia y procedimientos para la expropiación y remate de bienes controlados por la misma Junta. Poder Legislativo.

No. 8127 de junio de 1945. Se interpreta el artículo único de la Ley No. 26 del 17 de noviembre de 1944, en el sentido de que solamente los costarricenses naturales queden acogerse a sus beneficios que regulan las condiciones en que prisioneros de guerra, internados civiles en campos de concentración o que hayan padecido limitación de su libertad personal puedan reclamar indemnización. Poder Legislativo.

No. 221 de enero de 1945. Modifica el párrafo final del artículo 34 del decreto No. 15 del 1 de abril de 1943, referente a honorarios por gestiones judiciales en expropiaciones de bienes administrados por la Junta de Custodia. Poder Ejecutivo.

No. 999 de junio de 1945. Interpretando los decretos No. 29 del 13 de setiembre y No. 34 del 29 de octubre de 1942, se declara que sus disposiciones no se refieren a los billetes americanos, cuando su movilización es a favor del Estado y éste no actúa como mera persona civil. Poder Ejecutivo.

No. 1225 de junio de 1945. Se decreta la expropiación de una finca de Guillermo Niehaus \& Co. en Limón. Poder Ejecutivo.

No. 13423 de julio de 1945. Se suprime la Junta de Custodia de la Propiedad Enemiga y se mantiene la Oficina de Custodia. Poder Legislativo.

No. 19323 de agosto de 1945. Se reforma el párrafo segundo de la Ley No. 26 del 17 de noviembre de 1944, referente a indemnización de daños y perjuicios ocasionados con motivo de la guerra. Y se adiciona la referida Ley con disposiciones relativas a indemnizaciones para estaciones radiográficas de aficionados con equipos requisados. Poder Legislativo.

No. 1312 de noviembre de 1945. Se autoriza al Poder Ejecutivo para dar en pago al acreedor hipotecario y prendario Hans Rudolph Heinrich Traube el sobrante de la Hacienda Aragón, después de deducida la parte que se entregó al Instituto Interamericano de Ciencias Agrícolas. Poder Legislativo.

No. 1830 de julio de 1945. Se expropia inmueble de la Asociación Escolar Alemana de Costa Rica. Poder Ejecutivo. 
No. 1930 de julio de 1945. Se expropia inmuebles a Richard Steinvorth. Poder Ejecutivo.

No. 203 de agosto de 1945. Se expropia de unas fincas a la Sociedad Mercantil Guillermo Niehaus \& Co. Poder Ejecutivo.

No. 2210 de agosto de 1945. Se expropia una finca a la Asociación Escolar Alemana. Poder Ejecutivo.

No. 2417 de agosto de 1945. Se decreta la expropiación de diversas fincas pertenecientes a dieciocho súbditos alemanes. Poder Ejecutivo.

No. 2521 de agosto de 1945. Se deja sin efecto la expropiación de bienes de algunas personas dictada en decreto No. 24 del 17 de agosto de 1945. Poder Ejecutivo.

No. 3325 de setiembre de 1945. Se deroga la prohibición establecida por decreto No. 29 del 13 de setiembre de 1942, respecto a circulación de billetes americanos de 1, 2, 5, 10, y 20 dólares. Poder Ejecutivo.

No. 628 de setiembre de 1945. Se aprueba el reglamento para la venta y exportación de café de la cosecha 1945-46. Poder Ejecutivo.

No. 4416 de julio de 1945. Se excluyen de la custodia y control unos bienes de Margarita Fernández Jiménez de Steinvorth. Cartera de Hacienda y Comercio.

No. 4621 de julio de 1945. Se excluyen de la custodia y control los bienes de Carmen Andre Cañas de Siebe. Cartera de Hacienda y Comercio.

No. 5025 de julio de 1945. Se excluyen de la custodia y control los bienes de Wilheim Steinvorth Wasner. Cartera de Hacienda y Comercio.

No. 528 de agosto de 1945. Se excluyen de todo control del estado los bienes de María Obermayer Riederer de Staufer, Hedwig Klingholz Baer viuda de Wrether, Matilde Quesada Fleita de Schlager, José Staufer Solkner, Arturo Schlager Dautz, Carlos Werther Kligholz y José Schlager Dautz. Cartera de Hacienda y Comercio.

No. 5523 de agosto de 1945. Se eximen de todo control del Estado los bienes de Elsbeth Hoffman Justus de Knöhr. Cartera de Hacienda y Comercio.

No. 5624 de agosto de 1945. Se eximen de todo control del Estado los bienes de Max Buck Meyer, de su esposa Erna Beer Heinrich de 
Buck, Otto Knöhr Carranza, Eric Knöhr Zimmer, Ernesto Oeschler Martus. Cartera de Hacienda y Comercio.

No. 6718 de octubre de 1945. Se excluyen del control del Estado las propiedades de : Sophia Diepholz Diers, Emma Assmann Siebe de Dyes, Claudius Hedwig Brandt de Andre, Alberto Herring Billinger. Cartera de Hacienda y Comercio.

No. 795 de diciembre de 1945. Se excluyen del control del Estado los bienes de la empresa Lehmann \& Co. Cartera de Hacienda y Comercio.

No. 8111 de diciembre de 1945. Se eximen de todo control del Estado los bienes de Teodoro Assmann Turck. Cartera de Hacienda y Comercio.

No. 8319 de diciembre de 1945. Se reforma una resolución de la Oficina de Custodia para los efectos de la clasificación de las acciones de la Compañía Automotríz S.A. de acuerdo con las personas a quienes pertenecen. Cartera de Hacienda y Comercio.

No. 8419 de diciembre de 1945. Se exime del control a que han estado sometidos los bienes de Emma Siebe Beer de Asmann, Ana Siebe Beer de Lohrengel y Alexander Bierig Meyer. Cartera de Hacienda y Comercio.

Año 1946

No. 28 de enero de 1946. Se fijan los procedimientos que deben seguirse en caso de no haberse cumplido el requisito de declaración que exige el artículo 26 de la ley del 26 de diciembre de 1942, respecto a créditos activos o pasivos de extranjeros comprendidos en las listas proclamadas. Poder Ejecutivo.

No. 529 de enero de 1946. Determina la forma y las reglas que deben seguirse para la anotación y embargo de los bienes pertenecientes a ciudadanos de naciones enemigas, para el efecto de satisfacer el pago de las indemnizaciones de perjudicados. Poder Ejecutivo.

No. 1128 de marzo de 1946. Se decreta la expropiación de bienes de Botho y Gehrard Steinvorth Lauenstein y de Ricardo Steinvorth Ey. Poder Ejecutivo.

No. 1229 de enero de 1946. Se decreta la expropiación de fincas pertenecientes a la firma Guillermo Niehaus \& Co. en Limón. $\underline{\text { Poder }}$ Ejecutivo. 
No. 13 30 de marzo de 1946. Se decreta la expropiación de fincas de la Compañía Agrícola de Acosta, de Federico Reimers Wulí y de F. Reimers \& Co., en Limón, Guanacaste y San José. Poder Ejecutivo.

No. 143 de abril de 1946. Se decreta la expropiación de fincas de Pablo Spoerl Wolf, Karl Kitzing Jurgen, Compañía Agrícola de Acosta, Federico Reimers Wulf, Hans Niehaus Ahrens, Willy Niehaus Ahrens, Erwin Rafael Knöhr Carranza y A. F. Reimers \& Co. Poder Ejecutivo.

No. 156 de abril de 1946. Se decreta la expropiación de bienes de la Compañía Agrícola de Acosta y de Rodolfo Peters Scheider. $\underline{\text { Poder }}$ Ejecutivo.

No. 2222 de mayo de 1946. Se derogan los decretos ejecutivos No. 4 del 26 de mayo y No. 13 del 3 de julio de 1944, sobre expropiación de fincas de Marta Trejos González. Poder Ejecutivo.

No. 2812 de junio de 1946. Se limitan las atribuciones del Departamento de Cuotas de la Oficina de Defensa económica, y se suprime el Departamento de distribución de artículos de hule. Poder Ejecutivo.

No. 12 de enero de 1946. Se excluyen de todo control del Estado los bienes de María Eugenia Von Schroeter Riotte. Cartera de Hacienda y Comercio.

No. 816 de enero de 1946. Se excluyen de todo control del Estado los bienes de Emma Steinvorth Marín de Seevers. Cartera de Hacienda y Comercio.

No. 1225 de enero de 1946. Se excluyen de todo control del estado las propiedades de Segismundo de Prusia, Werner Thiele Hashagen y Carlos Otto Pilz Barm. Cartera de Hacienda y Comercio.

No. 1429 de enero de 1946. Se excluyen de todo control del Estado los bienes de Guillermo W. Thiele Hasshagen. Cartera de Hacienda y Comercio.

No. 1813 de febrero de 1946. Se excluyen de todo control del estado los bienes de Luise Leopold Schatte viuda de Schuster y de Gertrud Leopold Schatte. Cartera de Hacienda y Comercio.

No. 2727 de marzo de 1946. Se excluyen de todo control de Estado los bienes de Federico Schaubeck Auer y de Hilda Kansy Vougt de Ehehalt. Cartera de Hacienda y Comercio.

No. 3518 de mayo de 1946. Se excluyen de todo control del Estado los bienes de Ludwig Maximiliam Wimmer Finsterwalder, Henry Zehner, Annie Finsteralder viuda de Giebler y Oscar Hering Billinger. Cartera de Hacienda y Comercio. 
No. 3729 de mayo de 1946. Se excluye de todo control del Estado los bienes de Marta Trejos González. Cartera de Hacienda y Comercio.

No. 4014 de junio de 1946. Se excluye de todo control del Estado los bienes de Walter Siebe Beer y de Paul Theodor Bucher Degen. Cartera de Hacienda y Comercio.

No. 59612 de julio de 1946. Se ratifican las resoluciones de la Conferencia Interamericana sobre problemas de la Guerra y de la Paz, celebrada en México en febrero y marzo de 1945. Poder Legislativo.

No. 3726 de julio de 1946. Se deroga la prohibición del artículo $1^{\circ}$ del decreto No. 29 del 13 de setiembre de 1942, sobre circulación de billetes de cincuenta y de cien dólares de los Estados Unidos de América. Poder Ejecutivo.

No. 6121 de diciembre de 1946. Se adicionan las disposiciones de la ley No. 26 del 12 de diciembre de 1942, en lo relativo a subasta de bienes expropiados a extranjeros. Poder Ejecutivo.

No. 225 de octubre de 1946. A solicitud de Walter y Ludwing Otto Siebe Beer, de origen alemán, se les otorga la rehabilitación como costarricenses naturales por opción. Cartera de Relaciones Exteriores.

No. 6230 de julio de 1946. Se excluyen los bienes de Botho Steinvorth Lauenstein del control de la Junta de Custodia. Cartera de Hacienda y Comercio.

No. 7331 de agosto de 1946. Se excluyen del control de la Junta de Custodia los bienes de Wilhelm Peters Scheider y de Wilhelm Peters Schuster, de origen alemán. Cartera de Hacienda y Comercio.

No. 765 de setiembre de 1946. Se excluyen del control de la Junta de Custodia los bienes de Margarita Fernández Jiménez de Steinvorth. Cartera de Hacienda y Comercio.

No. 8217 de setiembre de 1946. Se excluyen del control de la Junta de Custodia los bienes de Gerardo Steinvorth Lauenstein, de origen alemán. Cartera de Hacienda y Comercio.

No. 10116 de octubre de 1946. Se excluyen del control de la Junta de Custodia los bienes de Jorge Seveers Steinvorth y Guillermo Von Breymann Figueroa. Cartera de Hacienda y Comercio.

No. 1188 de noviembre de 1946. Se excluyen del control de la Junta de Custodia los bienes de Paul Ehremberg Brinkmann. Cartera de Hacienda y Comercio. 
No. 11914 de noviembre de 1946. Se excluyen del control de la Junta de Custodia los bienes de Starr Pait Bruce de Gurke. Cartera de Hacienda y Comercio.

\section{Año 1947}

No. 2 14 de enero de 1947. Se excluyen del control del Estado los bienes de Gunther Freltag Kleefeld, Richard Schroeder, Gustavo Haeberle Schempp y Franz Miltenberger Heiter, alemanes. Cartera de Hacienda y Comercio.

No. 320 de enero de 1947. Se declara agotada la vía administrativa, para consentir en el remate ( por no admitir cómoda división), de una finca poseída en condominio por el Estado y Ernesto Steinvorth. Cartera de Hacienda y Comercio.

No. 622 de enero de 1947. Se excluyen de todo control por parte del Estado los bienes de Carlos Giegler Gross, ciudadano alemán. Cartera de Hacienda y Comercio.

No. 1728 de febrero d 1947. Se excluyen de todo control por parte del Estado los bienes de Erwin Grosser Bitzerg y de Federico Preinfald Seyld, alemanes. Cartera de Hacienda y Comercio.

No. 2821 de abril de 1947. Se recova autorización concedida a la Junta de Control de Exportación de Productos, para autorizar el pago de dividendos de accionistas del Banco Anglo Costarricense, residentes en el extranjero. Cartera de Hacienda y Comercio.

No. 3029 de abril de 1947. Se excluyen de todo control por parte del Estado los bienes de Carlos y Otto Guth Scharff. Cartera de Hacienda y Comercio.

No. 312 de mayo de 1947. Se excluyen de todo control por parte del Estado los bienes de Ernesto L. Lohrengel Siebe y de la empresa Agrícola Comercial Lohrengel S.A. Cartera de Hacienda y Comercio.

No. 3619 de mayo de 1947. Se excluyen de todo control por parte del Estado los bienes de Hans Fritz Adolf Alsleben Schulcke. Cartera de Hacienda y Comercio.

No. 3911 de junio de 1947. Se excluyen de todo control por parte del Estado los bienes de Max Paschka, ciudadano alemán. $\underline{\text { Cartera de }}$ Hacienda y Comercio.

No. 275 de agosto de 1947. Se deja sin efecto el decreto No. 14 del 3 de abril de 1946, que ordenó la expropiación de los bienes de Carl Kitzing Jurgen o Joergen. Poder Ejecutivo. 
No. 4411 de diciembre de 1947. Se deja sin efecto el decreto No. 14 del 3 de abril de 1946, que ordenó la expropiación de los bienes de Pablo Spoerl Wolf (sucesores). Poder Ejecutivo.

No. 453 de julio de 1947. Se excluye del control del Estado los bienes de Ernesto William Ey Gertenkorn, súbdito alemán. Cartera de Hacienda y Comercio.

No. 473 de julio de 1947. Se excluye del control del Estado los bienes de Emilio Dörsam Neurohr y de su esposa Isabel Schreiber Vinogradolf. Cartera de Hacienda y Comercio.

No. 488 de julio de 1947. Se excluye del control del Estado los bienes de Federico Karl Schad. Cartera de Hacienda y Comercio.

No. 5229 de julio de 1947. Se excluye del control del Estado los bienes de Margarita André Cañas de Albrecht. Cartera de Hacienda y Comercio.

No. 535 de agosto de 1947. Se excluye del control del Estado los bienes de Carl Jurguen Kitzing y de Annemarie Glatz Raatz de Kitzing. Cartera de Hacienda y Comercio.

No. 5512 de agosto de 1947. Se excluye del control del Estado los bienes de Federico Zeuner Witt y de Marta Fabian Nauté de Zeuner. Cartera de Hacienda y Comercio.

No. 594 de setiembre de 1947. Se excluye del control del Estado los bienes de Gabriela Mees Mayerhoffer viuda de Metger. Cartera de Hacienda y Comercio.

No. 7023 de setiembre de 1947. Se deniega la solicitud presentada por William Niehaus Ahrens para que se excluyan sus bienes del control del Estado. Cartera de Hacienda y Comercio.

No. 7326 de setiembre de 1947. Se excluye del control del Estado los bienes de Guillermo Bauer R. Cartera de Hacienda y Comercio.

No. 8013 de octubre de 1947. Se excluye del control del Estado el derecho de Ricardo Steinvorth de una fincas situadas en la provincia de Puntarenas. Cartera de Hacienda y Comercio. 
No. 10411 de diciembre de 1947. Se excluye del control del Estado los bienes de Pablo Spoerl Wolf y los de su viuda Federica Asmus

Schmidhauer. Cartera de Hacienda y Comercio.

\section{Año 1948}

No. 2520 de mayo de 1948. Se suprime la Oficina de Custodia. Junta Fundadora de la Segunda República.

No. 5915 de junio de 1948. Se derogan Leyes. Junta Fundadora de la Segunda República,

Año 1949

No. 43723 de marzo de 1949. Se intervienen libros de la Junta de Custodia.

Junta Fundadora de la Segunda República,

\section{Año 1960}

No. 266612 de noviembre de 1960. Restitución de bienes que fueron expropiados con motivo de la Segunda Guerra Mundial. Poder Legislativo.

\section{Año 1961}

No. 288824 de noviembre de 1949. Derogatoria del bloqueo económico. Poder Legislativo.

No. 294330 de noviembre de 1961. Se deroga Ley de Bloqueo Económico. Poder Legislativo.

Año 1966

No. 2416 de febrero de 1966. Visto el recurso administrativo de reposición o reconsideración que interpone Guillermo Niehaus y Co. Comandita por acciones, contra actos o disposiciones resultantes de resoluciones por Hacienda. Cartera de Hacienda. 


\section{Año 1970}

No. 414 de abril de 1970. Pago a la Sociedad Guillermo Niehaus y Co. en "Bonos de Conversión Vales de Expropiación." Cartera de Hacienda.

No. 426 de abril de 1970. Sin efecto avalúos de las fincas que representa Hans Niehaus Ahrens en condición de gerente de la Sociedad Guillermo Niehaus y Co. Cartera de Hacienda.

No. 14626 de mayo de 1970. Hans Niehaus Ahrens solicita reconvocatoria de la resolución de Hacienda por la Sociedad Guillermo Niehaus y Co. Cartera de Hacienda.

\section{Año 1974}

No. 828 de abril de 1974. Denegar reclamo del señor Hans Niehaus Ahrens en calidad de apoderado de la firma Niehaus y Co. para que el Estado pague "Depreciación de los Bonos Conversión Vales de Expropiación." Cartera de Hacienda.

No. 18219 de julio de 1974. Recurso de reposición de Fanny Quesada en condición de apoderada de la Sociedad Guillermo Niehaus y Co. Cartera de Hacienda. 